\title{
Modeling the Structural Relationship of Happiness Based on Psychological Well-Being With Self-efficacy Intermediation and Academic Self-regulation in University Students
}

\author{
Yahya Iri' ${ }^{\circledR}$, Mohammad Kazem Fakhri ${ }^{* \mathbb{(}}$, Ramazan Hassanzadeh' ${ }^{\mathbb{D}}$ \\ ${ }^{1}$ Department of Psychology, Sari Branch, Islamic Azad University, Sari, Iran
}

\begin{abstract}
Background: Happiness is the degree of emotion that a person judges with his overall quality of life as an utterly desirable life. The purpose of this study was to model the structural relationship between happiness based on psychological well-being and self-efficacy and self-regulatory mediation among students at Farhangian University.

Methods: This correlation study was carried out using structural equation modeling methods. The statistical population of this study included all undergraduate students at the Farhangian University of Golestan province who were studying in the academic year of 2016-17. By using the Morgan table, 280 people selected through multi-stage random cluster sampling. The data were collected using Savari and Arabzadeh's educational self-regulatory scale, Sherer Self-efficacy Scale, Oxford Happiness Questionnaire, and Ryff's psychological well-being questionnaire. Data analysis was performed using path analysis and structural equations with AMOS software.

Results: The results showed that psychological well-being had a positive effect on happiness $(P<0.02)$. Also, the pattern fit results showed that psychological well-being indirectly affects selfefficacy, and self-regulation has an indirect effect on happiness $(P<0.001)$.

Conclusion: The results of this study showed that there is a significant relationship between happiness and psychological well-being with self-efficacy and self-regulation mediation. Therefore, it is possible to raise the level of happiness and psychological well-being of students through the development of programs aimed at promoting self-efficacy and self-regulation of students.

Keywords: Happiness; Psychological well-being; Self-efficacy; Academic self-regulation; Students.
\end{abstract}

*Correspondence to Mohammad Kazem Fakhri, Department of Psychology, Sari Branch, Islamic Azad University, Sari, Iran. Tel: +9811-33032891, Email: fakhri@iausari.ac.ir

Published online August 31 2019

Citation: Iri Y, Fakhri MK, Hassanzadeh R. Modeling the structural relationship of happiness based on psychological well-being with self-efficacy intermediation and academic self-regulation in university students. Int Clin Neurosci J. 2019;6(3):104-110. doi:10.15171/ icnj.2019.20.

\section{Introduction}

Happiness is a kind of person's assessment of himself and his life and includes concepts such as life satisfaction, active affections, lack of symptoms of depression and anxiety. ${ }^{1}$ Happiness is the result of human judgment about how to live. Therefore, happiness based on personal attitude and perception, and it has a pleasant temperament that derives from positive experiences. ${ }^{2}$ Happy people have high standards of self-esteem and are more likely to think about their abilities and deal with stress. ${ }^{3}$ Nowadays, studies on happiness and its related factors are among the most important psychological priorities. Happiness has often considered as a multidimensional structure with two cognitive and emotional dimensions. Emotional dimension involves the existence of positive emotions and the absence of negative emotions and cognitive dimensions, including a general assessment of life that covers various areas. In other words, happiness does not just mean not to be sick but includes higher levels that affect both emotion and cognition. ${ }^{4}$ Happiness is one of the factors influencing psychological wellbeing, so that happiness means positive feeling, feeling of satisfaction and minimal negative feeling, and these three factors considered as three critical factors in psychological well-being. ${ }^{5}$ In addition, optimistic people show more effective coping behaviors, better and more valuable social relationships, higher flexibility, and more mental and physical well-being than pessimistic people. ${ }^{6}$ Psychological well-being refers to the experienced quality of life and reflects the optimal psychological experience.

Positive feeling and general satisfaction with life that includes self and others in different areas of family, occupation, a sense of well-being that involves the sense of coherence and continuity in life, emotional balance and

(C) 2019 The Author(s). This is an open access article distributed under the terms of the Creative Commons Attribution License (http:// creativecommons.org/licenses/by/4.0/), which permits unrestricted use, distribution, and reproduction in any medium, provided the original work is properly cited. 
overall satisfaction of life, and it means the actualization of all the talents of an individual. ${ }^{7}$ According to the statistics office of Iran, the number of students in the whole country estimated around 4 million, that the health of this young population is important in many aspects, including mental well-being, since many students exposed to psychological problems such as depression. ${ }^{8}$ Another important thing that can be a predictor of happiness is self-efficacy. Selfefficacy, assurance of their ability to successfully complete assignments, interact with others, and successful management of work and family. ${ }^{9,10}$ People with high selfefficacy, unlike people with low self-efficacy, use higherlevel intellectual processes to solve problems and imagine themselves successful in challenging assignments. ${ }^{11}$ In other words, self-efficacy is the perception of individuals of a specific range of abilities to perform the necessary actions to achieve valuable goals. ${ }^{12}$ The alignment of high-level happiness and self-efficacy motivates a person to maximize his potential learning abilities and achieve his potential. The active movement of people towards their goals is the cause of positive changes in their happiness. ${ }^{13}$ Academic self-regulation is one of the other factors affecting happiness in addition to psychological well-being and self-efficacy. Self-regulation refers to the processes in which people control their thoughts, feelings, and actions based on them. ${ }^{14}$ Zimmerman defines selfregulation as an active process of keeping thoughts, behaviors, and emotions in the pursuit of goals, and a self-regulating person has specific goals with certain strategies and monitors and evaluates his progress. ${ }^{15}$ Kitsantas and Zimmerman believe that self-regulated students use different methods to do their homework than persons with less self-regulation. ${ }^{16}$ Bembenutty during a study, showed that high self-regulated students tend to postpone their need satisfaction, have an intrinsic interest in the course, and exhibit more self-actualization to complete their learning tasks. ${ }^{17}$ Based on what has said, it can say that positive psychology is a new approach to contemporary psychology, which Seligman et al proposed, and introduced happiness and psychological well-being from the major issues raised therein. ${ }^{18}$ On the other hand, self-efficacy and self-regulation are factors that target and direct the activities, while improving individual self-esteem and ultimately giving a sense of value to each activity and performance, resulting in a thrill and a positive attitude. Regarding the variables in the present study, it seems that the relationships between predictive variables of happiness including psychological well-being and self-efficacy and academic self-regulation are not parallel, and psychological well-being, while directly related to happiness, predicts self-efficacy ${ }^{19}$ and self-regulatory education. ${ }^{20}$ Studies on the relationship between psychological well-being and happiness indicate that the relationship between these variables is very complicated. A review of the research suggests that, although the relationship between different psychological variables and these structures has been studied, the relationship between these structures has not been studied with each other. Therefore, due to the importance of the feeling of happiness and psychological well-being among students as the young people, increasing the number of students and lack systematic research on the feeling of psychological well-being in Iranian society, especially for students, the results of this study can improve micro, macro, educational, social, cultural and health planning and ultimately improving community health. The purpose of this study was to model the structural relationship between happiness and psychological well-being with self-efficacy intermediation and academic self-regulation among students at Farhangian University.

\section{Methods}

The present study was correlational with structural equation modeling test. The statistical population of this study consisted of all undergraduate students (male and female) of the Farhangian University of Golestan province (1100 students) in the academic year of 2015-2016, out of which 280 were selected by multi-stage random cluster sampling as sample size. (Because this study is a series of path analysis studies, for estimation of the sample size, the Kline's (2005) method was used). Thus, two universities have chosen from all universities of Farhangian in Golestan province, and two courses selected from the courses in both universities. Then, from each field of study, two classes were randomly selected. Before conducting the research and submitting a questionnaire, enough information about the subject has given to all students. Also, the satisfaction of all participants in the study has drawn. If a student did not want to attend the study, she/ he would not include in the study. It has also assured to all participants that their information would be confidential. The data were collected using a self-regulating educational scale of Savari and Arab-Zadeh, Sherer Self-efficacy Scale, Oxford Happiness Questionnaire, Reef's psychological well-being questionnaire. Data analysis was performed using path analysis and structural equations with AMOS software.

\section{Oxford Happiness Inventory OHI}

This tool was designed in 1990 by Argyll and Loo. This test consists of 29 questions of four options; each option's score is from 0 to 3 . Thus, the score that a subject can score on this scale is between $0-87$, with high scores representing higher happiness and lower scores for lower happiness. The reliability of the questionnaire has been reported by the alpha coefficient of 0.90 , and its test-retest reliability during the seven weeks was $0.78 .^{21}$ The validity and reliability of this questionnaire in this study were 0.75 and 0.78 , respectively.

\section{Ryff's Psychological Well-Being Questionnaire}

In 1989, this scale was designed by Ryff in 1989, and the 
original form of the questionnaire contains 120 items, but in subsequent studies, shorter forms of 84 items, 54 items, and 18 items were also proposed. ${ }^{22}$

How to score the Reef psychological well-being questionnaire based on the Likert scale of 6 degrees from 1 (totally opposite) to 6 (I totally agree). The questionnaire has six components and a total score. The higher the individual's score, the higher the psychological well-being. The Score of the Reef Psychological WellBeing Questionnaire has based on the Likert scale of 6 degrees from 1 (totally disagree) to 6 (totally agree). In the present study, the reliability coefficient by using test-retest method was 0.82 for the total score, and the reliability of subscales including self-acceptance, positive relationships with others, autonomy, environmental domination, purposeful life, and personal growth were $0.71,0.77,0.78$, $0.77,0.77$ and 0.78 respectively.

\section{Sherer General Self-efficacy Scale}

This scale has 17 questions that were developed by Sherer et al to measure general self-efficacy. ${ }^{23}$ The scoring of this scale is done based on Likert scale (from I completely disagree (score 1) to I completely agree (score 5), so the maximum score that a person can get from this scale is a score of 85 and a minimum score of 17 . The internal consistency coefficient of this scale is $0.83 .{ }^{24}$ Validity and reliability of this questionnaire were 0.77 and 0.84 , respectively.

\section{Educational Self-regulatory Scale}

This questionnaire was developed by Sevari and Arabzadeh in 2013 and consists of 30 questions, which consists of 6 subscales: memory strategy (5 questions), targeting (3 questions), self-assessment (6 questions), assistance request (6 questions), accountability (4 questions) and organization (6 questions). Scoring the questionnaire is as a spectrum of "completely disagreeing," "disagreeing," "disregarding," "agreeing" and "totally agreeing" with 1, 2, 3, 4, and 5, respectively. Sevari and Arabzadeh's reliability of this questionnaire through Cronbach's alpha for the whole questionnaire is 0.87 , for the strategy of memory 0.74 , for targeting 0.75 , for self-evaluation 0.83 , for assistance 0.71 , for accountability 0.72 and 0.76 for organizing. Meanwhile, its validity has verified through confirmatory factor analysis. ${ }^{25}$

\section{Results}

Of the 280 students, 271 responded to the questionnaires. The mean and standard deviation of the age of male and female students were $23.4 \pm 6.4$ and $23.8 \pm 6.8$ years, respectively, with an age range of 20 to 30 years. One hundred thirty-five male students and $94.66 \%$ of them were single. Demographic information is presented in Table 1, identified down by marital status and gender.

Descriptive findings, including mean and standard deviation, happiness scores, psychological well-being, self-efficacy, and self-regulation, presented in Table 2.

The Kolmogorov-Smirnov test was used to test the data. The results of this test showed that the data have a normal distribution then parametric analyzes can be used for it. For estimation of Alco, the maximum correctness method, root mean square error of approximation (RMSEA), standardized root mean square residua (SRMR), comparative fit index (CFI), normed fit index (NFI), goodness of fit index (GFI), adjusted goodness of fit index (AGFI) have been used.

As shown in Table 3, all fit indices are above 0.90; therefore, these indices show that the developed model has a favorable fit. RMSEA was 0.07. Given that, the value of less than 1 for this indicator is desirable, so the model is also in an acceptable range for this indicator.

The value of the chi-square in the model is 13.68 , and the degree of freedom of the model is equal to 1 , resulting in their ratio of 2.60 , considering that it is in the range of 1 to 3 , then the model is also desirable for this index. Therefore, the developed model has a good fit. Table 3 indicates the standard coefficients of variables effect upon each other.

Table 4 shows the coefficients of predictive paths of happiness. The path analysis coefficients showed that the direct path to psychological well-being was significant

Table 1. Sample Frequency Distribution Based on Gender and Marital State

\begin{tabular}{llll}
\hline Variables & & No. & $\%$ \\
\hline \multirow{2}{*}{ Gender } & Male & 135 & 49.82 \\
& Female & 136 & 50.18 \\
\multirow{2}{*}{ Marital state } & Single & 256 & 94.46 \\
& Married & 15 & 6.54 \\
\hline
\end{tabular}

Table 2. Descriptive Indexes of Mean and Standard Deviation, in Happiness, Self-regulation, Self-efficacy and Psychological Well-Being

\begin{tabular}{llll}
\hline Variables & & Mean & SD \\
\hline \multirow{3}{*}{ Happiness } & Life satisfaction & 22.17 & 12.75 \\
& Self-esteem & 9.98 & 9.98 \\
& Well-being & 22.20 & 12.74 \\
& Satisfaction & 12.58 & 6.13 \\
& Positive mood & 12.80 & 6.12 \\
& Self-admission & 41.01 & 15.15 \\
Psychological well- & Positive relationships & 41.06 & 15.07 \\
being & Autonomy & 41.31 & 15.55 \\
& Dominate the environment & 42.04 & 16.29 \\
& Purpose in life & 41.68 & 17.25 \\
& Personal growth & 41.75 & 17.03 \\
Self-efficacy & Desire to start & 15.39 & 6.21 \\
& Comprehensive effort & 17.82 & 7.13 \\
& Facing with events & 17.84 & 7.16 \\
& Memory & 35.30 & 12.59 \\
& Targeting & 13.01 & 4.84 \\
& Responsibility & 35.34 & 12.56 \\
& Organizing & 15.03 & 6.21 \\
& Assistance Request & 18.98 & 6.83 \\
& Self-assessment & 30.20 & 10.71 \\
\hline
\end{tabular}


Table 3. Fit Indicators of Data Analysis

\begin{tabular}{lc}
\hline Indexes & Finding \\
\hline Chi-square test & 2.60 \\
$P$ value & 0.01 \\
Degree freedom (df) & 1 \\
Root mean square error of approximation (RMSEA) & 0.07 \\
The goodness of fit index (GFI) & 0.99 \\
Adjusted goodness of fit index (AGFI) & 0.95 \\
Normed fit index (NFI) & 0.97 \\
Comparative fit index (CFI) & 0.98 \\
Incremental fit index (IFI) & 0.98 \\
Tucker Lewis index (TLI) & 0.91 \\
Root mean square error of approximation & 0.07 \\
\hline
\end{tabular}

toward happiness $(P<0.02, \beta=0.30)$. Also, the path of psychological well-being was significant toward selfefficacy $(P<0.001, \beta=0.69)$ and self-regulation $(P<0.001$, $P=0.26)$. On the other hand, the self-regulation variable was significantly related to self-efficacy $(P<0.01, \beta=0.20)$, finally, the self-regulation pathway was significant toward happiness $(P<0.001, \beta=0.22)$. Additional information has given in Table 4 .

The bootstrap command has used for estimating and determining the indirect route from AMOS software. As the results of Table 5 show, the indirect routes of the model are significant. This shows that the role of mediator of self-efficacy and self-regulation in the relationship between psychological well-being and happiness is significant $(P<0.002)$. Finally, in Figure 1 , the final model is based on the results of the study.

\section{Discussion}

The purpose of this study was to investigate the structural relationship between happiness and psychological well-being through self-efficacy and self-regulation. The research findings showed that there is a positive relationship between psychological well-being and happiness and psychological well-being has a direct effect on happiness. These findings are consistent with the results of Akbarian, ${ }^{26}$ Zadhasan et al, ${ }^{27}$ Amiri et al, ${ }^{28}$ Yousefi and Khayatan, ${ }^{29}$ Gholipour, ${ }^{30}$ Diener $^{31}$, Diener et $\mathrm{al}^{32}$ and Stieger et $\mathrm{al}^{33}$ studies. In explaining this finding, happiness is a positive feeling, a sense of satisfaction and a negligible negative feeling, which are three important factors in psychological well-being and are considered to be psychological well-being emotional (emotional) components. Psychological well-being has a significant contribution to the various aspects of people's lives, such as social acceptance, having relationships with people, intimacy, feeling of efficiency, and having a social status, it means the actualization of all the talents of an individual. Anderson believes that happy people tend to see themselves and others as positive and interpret events positively. They do not think much about defeat, they make reasonable decisions on the opportunities they make, and they have realistic optimism about the events. As a result, happy people who experience more positive emotions, are happier and, consequently, feel better in evaluating their lives, and thus experience a higher quality of life. ${ }^{34}$ Other results of the study showed that psychological well-being has an indirect effect through self-efficacy on happiness. This is consistent with the findings of Abdel-Khalek and Lester $^{35}$ and Hunagund and Hangal. ${ }^{36}$ Self-efficacy is one of the important variables related to psychological wellbeing. In Bandura's theory, the concept of self-efficacy is a sense of competence and ability to stay alive with life. In fact, Bandura considers self-efficacy as a person's perception of a degree of control. ${ }^{37}$ With increasing selfefficacy, the individual's performance increases. Following this, stress and anxiety decrease and lead to psychological well-being resulting in happiness. In fact, joy has been associated with human issues throughout history as an effective way of coping with issues and problems and has a close relationship with self-efficacy. The alignment of happiness and self-efficacy means that one uses the full potential of his learning potential. Happy people recall positive events more than negative, and thus exchange positive energy with the environment and improve their relationships with them. In addition, based on the results of psychological well-being, self-regulation has an indirect effect on self-regulation. These findings are consistent with the findings of Ghorbani and Foladchang, ${ }^{38}$ Asghari et $\mathrm{al},{ }^{39}$ Kindekens et $\mathrm{al},{ }^{13}$ Stieger et $\mathrm{al},{ }^{33}$ Cleary et $\mathrm{al},{ }^{40}$ and Zhang et al. $^{41}$ In explaining the findings, it can be said

Table 4. Results of Prediction Predictors of Happiness

\begin{tabular}{|c|c|c|c|c|c|}
\hline Variables Relations of the Model & Estimated Value & $\beta$ & Standard Error & $\mathbf{T}$ & $P$ Value \\
\hline Psychological well-being upon happiness & 0.064 & 0.30 & 0.02 & 2.12 & 0.02 \\
\hline Psychological well-being upon self-efficacy & 0.62 & 0.69 & 0.03 & 9.20 & 0.001 \\
\hline Psychological well-being upon self-regulation & 0.25 & 0.26 & 0.04 & 3.67 & 0.001 \\
\hline Self-regulation upon self-efficacy & 0.8 & 0.29 & 0.02 & 2.46 & 0.001 \\
\hline Self-regulation upon happiness & 0.03 & 0.22 & 0.01 & 4.13 & 0.001 \\
\hline
\end{tabular}

Table 5. Indirect Estimation of The Model Using the Bootstrap Estimation Method

\begin{tabular}{lllll}
\hline Indirect Path & Value & Lower & Upper & P-value \\
\hline Psychological well-being to happiness by mediator role of self-efficacy \& self-regulation & 0.30 & 0.12 & 0.49 \\
\hline
\end{tabular}




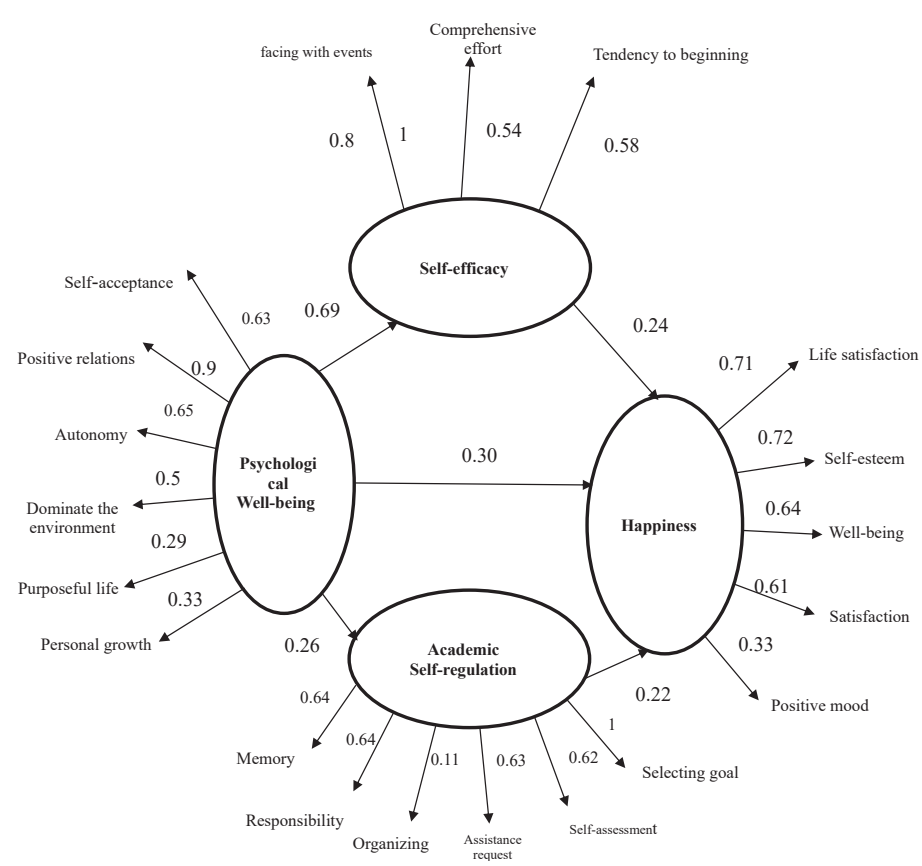

Figure 1. The Proposed Model of the Relationship Between Happiness and Psychological Well-Being With the Role of Self-efficacy and Self-regulation Mediation.

that students who have high self-regulation show higher levels of self-efficacy and potential ability to solve the problem, and this is clearly related to their mental health. According to Kindekens et al study, ${ }^{13}$ the psychological well-being of students depends on their self-regulation strategies. The self-regulating student knows from experience and in terms of his abilities that what can be done with the help of others, including friends, parents, and teachers, and this makes it possible to maintain psychological well-being without suffering pressure while maintaining academic and occupational success. Self-regulating individuals can well evaluate stressful events and find ways to deal with them and properly adjust their emotions in different situations. ${ }^{13}$ Individuals can change their way of thinking to themselves and the world through self-regulation, and this change is through cognitive control and the substitution of positive thoughts instead of negative thoughts. According to Seligman et $\mathrm{al},{ }^{18}$ self-regulatory education prompts the learner to target his or her behavior effectively. The self-regulating learner is purposeful and is, therefore, well-being and happiness. This sense of happiness and self-satisfaction motivates the person for the next activity. Therefore, a self-regulating student has a greater sense of control and planning on his or her own actions and is psychologically more self-confident. Psychological well-being through self-regulation and self-efficacy has indirect effects on happiness. Gholipour study also showed that self-efficacy could increase psychological well-being and happiness as a mediator. ${ }^{30}$ In addition, Hassan Nia et al have pointed out the role of mediating self-regulation and self-efficacy on happiness. ${ }^{42}$ Self-efficacy beliefs, both in the present and over time, have a positive effect on success. These self-efficacy beliefs in adolescents manage emotions, improve interpersonal relationships, create positive expectations about the future, maintain high self-esteem, and a sense of satisfaction from life. The self-regulating learner emphasizes self-control and afterward assesses the activities performed. These people usually feel satisfied with their efforts. In other words, they will have more selfefficacy than others. The limitations of this study is the data that was collected using a questionnaire that may be prone to distortion due to the unconscious bias of many respondents. In addition, this research has been carried out in Golestan province; therefore, the generalization of results to other cities should be cautious.

\section{Conclusion}

The results of this study showed that there is a significant relationship between happiness and psychological wellbeing with self-efficacy and self-regulation mediation. Regarding these results, it has suggested that the factors affecting the growth of well-being and happiness in the students should use in individual and group counseling sessions. On the other hand, by developing policies and implementing programs aimed at improving selfefficacy and self-regulation of students, they can raise their happiness and psychological well-being. It is also possible to identify the factors affecting the psychological well-being and happiness according to their educational environment while recognizing the psychological trauma in order to improve and increase the psychological well- 
being and happiness.

\section{Conflict of Interest Disclosures}

The authors declare that they have no conflict of interests.

\section{Ethical Statement}

Before conducting the research and submitting a questionnaire, enough information about the subject has given to all students, and the satisfaction of all participants in the study has drawn. If a student did not want to attend the study, she/he would not include in the study. It has also assured to all participants that their information would be confidential.

\section{References}

1. Cavazos Vela J, Castro V, Cavazos L, Cavazos M, Gonzalez SL. Understanding Latina/o students' meaning in life, spirituality, and subjective happiness. J Hispanic High Educ. 2015;14(2):171-84. doi: 10.1177/1538192714544524.

2. Lane T. How does happiness relate to economic behaviour? A review of the literature. J Behav Exp Econ. 2017;68:62-78. doi: 10.1016/j.socec.2017.04.001.

3. Boehm JK, Kubzansky LD. The heart's content: the association between positive psychological well-being and cardiovascular health. Psychol Bull. 2012;138(4):655-91. doi: 10.1037/ a0027448.

4. Fatima S, Sharif S, Khalid I. How does religiosity enhance psychological well-being? Roles of self-efficacy and perceived social support. Psycholog Relig Spiritual. 2018;10(2):119-27. doi: 10.1037/rel0000168.

5. Lyubomirsky S, Sheldon KM, Schkade D. Pursuing happiness: The architecture of sustainable change. Rev Gen Psychol. 2005;9(2):111-31. doi: 10.1037/1089-2680.9.2.111.

6. Lau S, Kubiak T, Burchert S, Goering M, Oberlander N, von Mauschwitz $\mathrm{H}$, et al. Disentangling the effects of optimism and attributions on feelings of success. Pers Individ Dif. 2014;56:78-82. doi: 10.1016/j.paid.2013.08.030.

7. Huang $\mathrm{H}$, Humphreys BR. Sports participation and happiness: Evidence from US microdata. J Econ Psychol. 2012;33(4):77693.

8. Rezaei T, Yazdi-Ravandi S, Ghaleiha A, Seif Rabiei MA. Depression among medical students of Hamadan University of Medical Sciences in 2014: The Role of demographic variables. Pajouhan Scientific Journal. 2015;13(4):1-8.

9. Yazdi-Ravandi S, Taslimi Z, Ahmadpanah M, Ghaleiha A. Adjustment to diabetes among diabetic patients: the roles of social support and self-efficacy. Avicenna Journal of Neuro Psycho Physiology. 2016;3(1):e37470. doi: 10.17795/ ajnpp-37470.

10. Ozer EA, Akgun OE. The effects of irrational beliefs on academic motivation and academic self-efficacy of candidate teachers of computer and instructional technologies education department. Procedia Soc Behav Sci. 2015;197:1287-92. doi: 10.1016/j.sbspro.2015.07.401.

11. Hazan-Liran B, Miller P. The role of psychological capital in academic adjustment among university students. J Happiness Stud. 2019;20(1):51-65. doi: 10.1007/s10902-017-9933-3.

12. Yazdi-Ravandi S, Taslimi Z, Jamshidian N, Saberi H, Shams J, Haghparast A. Prediction of quality of life by self-efficacy, pain intensity and pain duration in patient with pain disorders. Basic Clin Neurosci. 2013;4(2):117-24.

13. Kindekens A, Reina VR, De Backer F, Peeters J, Buffel T, Lombaerts $\mathrm{K}$. Enhancing student wellbeing in secondary education by combining self-regulated learning and arts education. Procedia Soc Behav Sci. 2014;116:1982-7. doi: 10.1016/j.sbspro.2014.01.507.

14. 14. Schmeichel BJ, Zell A. Trait self-control predicts performance on behavioral tests of self-control. J Pers. 2007;75(4):743-55. doi: 10.1111/j.1467-6494.2007.00455.x.

15. Zimmerman BJ. Becoming a self-regulated learner: An overview. Theory Pract. 2002;41(2):64-70. doi: 10.1207/ s15430421tip4102_2.

16. Zimmerman BJ, Kitsantas A. Comparing students' selfdiscipline and self-regulation measures and their prediction of academic achievement. Contemp Educ Psychol. 2014;39(2):145-55. doi: 10.1016/j.cedpsych.2014.03.004.

17. Bembenutty $\mathrm{H}$. Homework completion: The role of selfefficacy, delay of gratification, and self-regulatory processes. Int J Educ Psychol Assess. 2010;6(1):1-20.

18. Seligman ME, Steen TA, Park N, Peterson C. Positive psychology progress: empirical validation of interventions. Am Psychol. 2005;60(5):410-21. doi: 10.1037/0003-066x.60.5.410.

19. Mikolajczak $M$, Luminet $O$. Trait emotional intelligence and the cognitive appraisal of stressful events: An exploratory study. Pers Individ Dif. 2008;44(7):1445-53. doi: 10.1016/j. paid.2007.12.012.

20. Mabekoje SO. Emotional intelligence and self-regulation among school-going adolescent: Self-efficacy as a mediator. Cotemporary Humanities. 2010;4(2):209-22.

21. Hills P, Argyle M. The Oxford Happiness Questionnaire: a compact scale for the measurement of psychological wellbeing. Pers Individ Dif. 2002;33(7):1073-82. doi: 10.1016/ S0191-8869(01)00213-6.

22. Ryff CD, Singer BH. Best news yet on the six-factor model of well-being. Soc Sci Res. 2006;35(4):1103-19. doi: 10.1016/j. ssresearch.2006.01.002.

23. Sherer M, Maddux JE, Mercandante B, Prentice-Dunn S, Jacobs B, Rogers RW. The self-efficacy scale: Construction and validation. Psychol Rep. 1982;51(2):663-71. doi: 10.2466/ pro.1982.51.2.663.

24. Lo SH, Chang AM, Chau JP. Translation and validation of a chinese version of the stroke self-efficacy questionnaire in community-dwelling stroke survivors. Top Stroke Rehabil. 2016;23(3):163-9. doi: 10.1080/10749357.2015.1122265.

25. Sevari K, Arabzadeh SH. Construction and measurement of the psychometric properties of academic self- regulation questionnaire. J Sch Psychol. 2013;3(2):75-92.

26. Akbarian F. On the relationship between religious attitude and happiness and self-efficacy of high school students. J Sch Psychol. 2016;5(2):7-19.

27. Zadhasan Z, Dehghanpour M, Bastami M, Yarahmadi H. The relationship between happiness and psychological well-being with job satisfaction of Khuzestan Military Hospital Nurses. Nurse and Physician within War. 2017;5(15):11-9. [Persian].

28. Amiri S, Sepehrian Azar F, Ghasemi Navab A. Invastigate psychological well-being, happiness and emotion regulation in dark triad personality tendencies. J Psychol Stud. 2017;13(2):25-42. doi: 10.22051/psy.2017.14547.1370.

29. Yousefi M, Khayatan F. Comparison of happiness, psycholigy well-being and job perfectionism among women nurses of different sections of haspitals in Isfahan at 2014. Scientific Journal of Hamadan Nursing \& Midwifery Faculty. 2015;23(2):52-62. [Persian].

30. Gholipour N. Study of the relationship between metacognitive beliefs and self-efficacy, happiness and psychological wellbeing in students of distance education schools. The Journal of New Advances in Behavioral Science. 2018;3(20):51-64. [Persian].

31. Diener E. New findings and future directions for subjective well-being research. Am Psychol. 2012;67(8):590-7. doi: 10.1037/a0029541.

32. Diener E, Tay L, Myers DG. The religion paradox: if religion makes people happy, why are so many dropping out? J Pers 
Soc Psychol. 2011;101(6):1278-90. doi: 10.1037/a0024402.

33. Stieger S, Formann AK, Burger C. Humor styles and their relationship to explicit and implicit self-esteem. Pers Individ Dif. 2011;50(5):747-50. doi: 10.1016/j.paid.2010.11.025.

34. Anderson KL, Burckhardt CS. Conceptualization and measurement of quality of life as an outcome variable for health care intervention and research. J Adv Nurs. 1999;29(2):298-306.

35. Abdel-Khalek AM, Lester D. The association between religiosity, generalized self-efficacy, mental health, and happiness in Arab college students. Pers Individ Dif. 2017;109:12-6. doi: 10.1016/j.paid.2016.12.010.

36. Hunagund DL, Hangal SJ. Self-efficacy and happiness in youth. J Indian Acad Appl Psychol. 2014;40(1):70-3

37. Bandura A. On the functional properties of perceived selfefficacy revisited. Journal of Management. 2012;38(1):9-44. doi: 10.1177/0149206311410606.

38. Ghorbani R, Fooladchang M. The relation of self-regulation and communal mastery to psychological well-being. Research in School and Virtual Learning. 2015;2(8):31-42.
39. Asghari F, Saadat S, Atefi Karajvandani S, Janalizadeh Kokaneh $\mathrm{S}$. The relationship between academic self-efficacy and psychological well-being, family cohesion, and spiritual health among students of kharazmi university. Iran J Med Educ. 2014;14(7):581-93.

40. Cleary TJ, Velardi B, Schnaidman B. Effects of the SelfRegulation Empowerment Program (SREP) on middle school students' strategic skills, self-efficacy, and mathematics achievement. J Sch Psychol. 2017;64:28-42. doi: 10.1016/j. jsp.2017.04.004.

41. Zhang Y, Dong S, Fang W, Chai X, Mei J, Fan X. Self-efficacy for self-regulation and fear of failure as mediators between selfesteem and academic procrastination among undergraduates in health professions. Adv Health Sci Educ Theory Pract. 2018;23(4):817-30. doi: 10.1007/s10459-018-9832-3.

42. Hassan Nia S, Saleh Sedghpour B, Ibrahim Damavandi M. Modeling the structural relationship of emotional intelligence and happiness with intermediate of self-efficacy and academic self-regulatory. J Teach Learn. 2014;6(2):32-60. 